\title{
フラックス法によるウォラストナイトの結晶成長
}

\author{
瀬戸口正広・坂 本千秋 \\ （大阪工業技術試験所）
}

\section{Crystal Growth of Wollastonite from NaCl Flux}

\author{
By \\ Masahiro SETOGUCHI and Chiaki SAKAMOTO \\ (Government Industrial Research Institute, Osaka)
}

\begin{abstract}
Studies on crystal growth of wollastonite $\left(\beta-\mathrm{CaSiO}_{3}\right)$ were attempted by slow cooling from $\mathrm{NaCl}$ flux.

The solubility of $\mathrm{CaSiO}_{3}$ in $\mathrm{NaCl}$ was very low with $0.09 \mathrm{wt} \%$ at $1010^{\circ} \mathrm{C}$ and 0.42 wt $\%$ at $1190^{\circ} \mathrm{C}$. The mixtures consisting of the $2 \sim 3 \mathrm{wt} \%$ of synthetic wollastonite in $\mathrm{NaCl}$ of $20 \sim 45 \mathrm{~g}$, in excess to its solubility, in the Pt crucible were soaked for $0 \sim 24$ hours at $1080^{\circ} \sim 1200^{\circ} \mathrm{C}$ and then cooled to about $800^{\circ} \mathrm{C}$ with a rate of $5^{\circ} \mathrm{C}$ per hour.

On crystal growth from above $1125^{\circ} \mathrm{C}$, both crystals of pseudowollastonite $\left(\alpha-\mathrm{CaSiO}_{3}\right)$ and wollastonite were obtained, the former was stable above $1125^{\circ} \mathrm{C}$ and the latter was stable below $1125^{\circ} \mathrm{C}$.

The wollastonite crystals grown by a soaking at $1200^{\circ} \mathrm{C}$ for 24 hours were large in size and small by number, for they would have grown from only a few spontaneous nuclei on the upper wall of the crucible. For the soaking at $1150^{\circ} \mathrm{C}$, it was found that they were small in size and large by number. These seemed to be formed from much nuclei from the unsolved residues which were excess to its solubility in the bottom of the crucible.

The wollastonite crystals, needle-shaped as large as $6 \mathrm{~mm}$ in length and $0.3 \mathrm{~mm}$ in diameter, were grown along $b$-axis and they took usually single crystal and sometimes twinned crystal.

[Received May 24, 1967]
\end{abstract}

\section{1. 緒 锗 \\ ウォラストナイト $\left(\beta-\mathrm{CaSiO}_{3}\right)$ の多結晶体は, 誘電} 体損失が小さいので高周波絶縁材料 ${ }^{11}$, あるいは活性化


究が行なわれている。この場合, 単結晶をえることがで きれば,これらの詳しい物理測定および結晶構造の解析 などを行ならことができる。

ウォラストナイトは天然では接触変成岩中に, 人工で はスラグやソーダ石灰ガラス中に長さ数 $\mathrm{mm}$ の単結晶 として産する。しかし，乙机らは不純物を含有し，ま た，その分離が容易でないので，紋粹な結晶をえるた め,または結晶に必要な不純物を含有させるために流、 人工的に育成しなければならない。

いっぽう， $\mathrm{CaSiO}_{3}$ の融点は $1540^{\circ} \mathrm{C}$ であるが，ウォ ラストナイトに変態があり $1125^{\circ} \mathrm{C}$ 以上では擬ウォラス トナイト $\left(\alpha-\mathrm{CaSiO}_{3}\right)$ が安定である・したがって，この 転移点以下で安定なウォラストナイトの結晶は $1125^{\circ} \mathrm{C}$ 以下で成長させなければならない。ささらに, 一般に珪酸 塩の熔融体は粘性が大であり，純料組成の熔融体からは 大きい単結晶をえることが困難である。したがって, ウ オラストナイトの結晶成長を行なうには，フラックス法

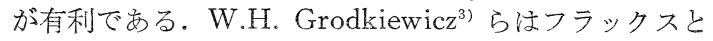
して $\mathrm{PbO}$ を使用しウォラストナイトの結晶成長を行 ない，その結晶について簡単に報告している。この方法 では目的の結晶であるウォラストナイトが酸溶解性であ るため, フラックスと結晶の分離が難かしいと考えられ る。

著者らは， $\mathrm{NaCl}$ などのアルカリおよびアルカリ土類 の塩化物をフラックスとし, 徐冷法によってウォラスト ナイトの結晶成長を計った。 これらのフラックスは水溶 性であるので, 目的の成長した結晶との分離が容易であ る. 実験の結果, 直径 $0.3 \mathrm{~mm}$, 長さ $6 \mathrm{~mm}$ 亿達する針 状の単結晶を成長させることができたので, 以下その成 長法について報告する。

\section{2. 穾 験 方 法}

フラックス法によって結晶を成長させるにはまず， 溶剂となる塩類を熔融し，これに目的とする結晶の成 分, すなわち, 出発原料を飽和するまで溶解させる. つ ぎに全体を徐冷して, 目的の結晶を晶出させるのである から, 出発原料はもとよりフラックスの適性および温度 の設定などが大切である。 


\section{1 出発原料の調製}

出発原料は 4 種類使用したが。これらはつぎのように 調製した。

(1) $\mathrm{SiO}_{2}$ (石英) と $\mathrm{CaCO}_{3}$ の等モル混合物

(2) $\alpha-\mathrm{CaSiO}_{3}$

(2)については，(1)を白金坩堝中 $1580^{\circ} \mathrm{C} て ゙$ 熔融した 後，水中へ投入して急冷させ，その中から結晶質の部分 のみをピンセットで選別したものである.

(3) $\beta-\mathrm{CaSiO}_{3}$

(3)は，まず，結晶質の $\alpha-\mathrm{CaSiO}_{3}$ と同時に生成したガ ラス質部分 $\left(\mathrm{CaSiO}_{3}\right.$ 加なる $)$ との混合物を粉砕す る.つぎに，これを $1050^{\circ} \mathrm{C} て ゙ ~ 24$ 時間熱処理して転移 させたものである.

(4) 天然ウォラストナイト $\left(\beta-\mathrm{CaSiO}_{3}\right)$

以上(1)から (4)までの出発原料は，いずれも瑪玹乳鉢で充 分粉砕混合した後使用した。これらの原料について，あ らかじめ X 線回折によって調べた結果を図一1に示 す。図から明らかなように, 上記(3)の $\beta-\mathrm{CaSiO}_{3}$ 中に は未転移の $\alpha-\mathrm{CaSiO}_{3}$ が少量含まれていた。

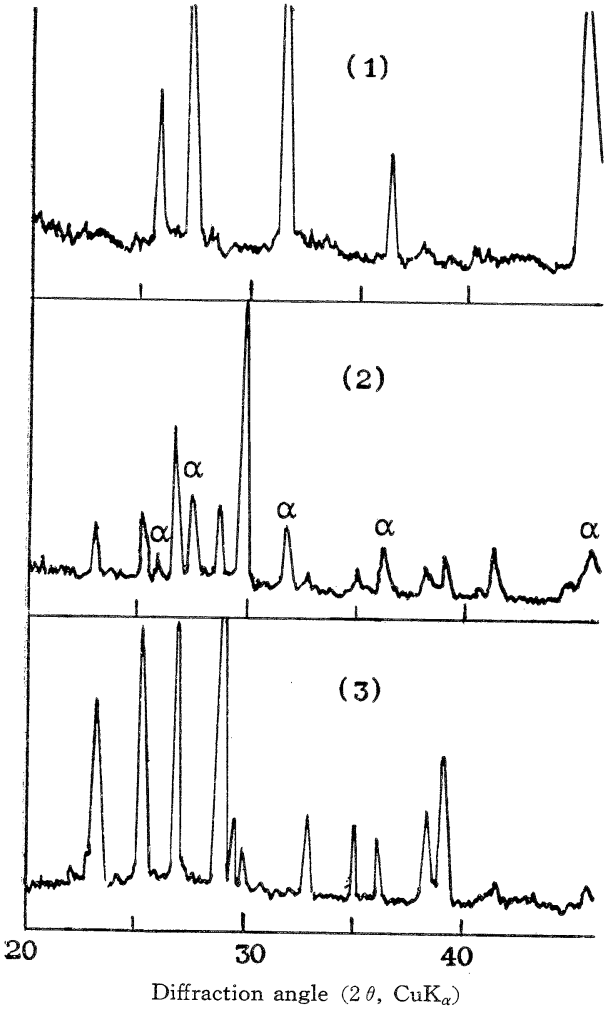

(1) $\alpha-\mathrm{CaSiO}_{3}$, (2) Synthetic $\beta-\mathrm{CaSiO}_{3}$, (3) Natural $\beta-\mathrm{CaSiO}$

Fig. 1. X-ray diffraction patterns of the starting materials for crystal growth of wollastonite.

\section{2 フラックスとしての適性}

フラックスは，出発原料と反応せず，これをよく溶解 するが一方では成長した目的の結晶体との分離が容易で
なければならない，以上の適性を調べるために，アルカ リおよびアルカリ土類の塩化物, すなわち, $\mathrm{NaCl}, \mathrm{KCl}$, $\mathrm{LiCl}$ および $\mathrm{CaCl}_{2}$ について, 2.4 項の結晶成長方法に より検討した。

\section{3 溶解度の測定方法}

結晶成長を行なうには，まずフラックス中における目 的の結晶成分の溶解度を知る必要がある。そこで, $\mathrm{NaCl}$ のフラックス中でその溶解度を測定した。すなわち， $50 \mathrm{cc}$ の白金坩堝を使用し， $45 \mathrm{~g}$ の NaCl に対し $\beta$ $\mathrm{CaSiO}_{3}$ を約 $1 \mathrm{~g}$ の割合で混合後, 所定温度で 5 時間熔 融を行なう．この操作によって溶質は充分溶解するが， 溶解度以上の過剩の成分は坩堝の底に沈着する。ここで 生じた上澄液の約 $10 \mathrm{~g}$ を迅速に他の白金坩堝へ移した 後,このものにについて分析を行なった。すなわち，キ レート滴定によって試料中の $\mathrm{Ca}$ のみを定量した後，こ れを $\mathrm{CaSiO}_{3}$ 亿換算して溶解した溶質の量とした。な お, 以上の操作は, 横型環状電気炉を使用し, 測定の温 度誤差は $\pm 1^{\circ} \mathrm{C}$ 以内に保った。

\section{4 結晶の成長方法}

後述する3.1 項の結果から, $20 \mathrm{~g}$ または $45 \mathrm{~g}$ の $\mathrm{NaCl}$ をフラックスとし，これに対して出発原料を 2 〜 \% （以下すべて重量％とする）混合する。これらを 30 cc または $50 \mathrm{cc}$ の蓋付白金坩堝中へ投入し, 空気流中 で加熱した。試料は，まず $1000^{\circ} \sim 1200^{\circ} \mathrm{C}$ における所 定の最高温度*まで，4 6 時間かかって加熱された。つ ぎに，その温度で $0 \sim 48$ 時間の範囲の所要時間を一定 温度保った後, $5^{\circ} \mathrm{C} / \mathrm{hr}$ の降温速度で約 $800^{\circ} \mathrm{C}$ まで徐 冷する．以上の操作によって結晶成長が行なわれた。な お, この間の炉温の温度変動は $\pm 5^{\circ} \mathrm{C}$ であった. 最徐 に炉内の試料は約 $800^{\circ} \mathrm{C}$ 加放冷を行ない，温水によ って試料中のフラックスを溶解し，分離された目的の結 晶について, 偏光影微鏡観察および X 線回折実験に供 した。

\section{3. 結果}

\section{1 フラックスとしての適性および溶解度}

フラックスとして実験に使用したアルカリ㧍よびア ルカリ土類塩化物中, $\mathrm{NaCl}$ からは比較的大きな $\beta$ $\mathrm{CaSiO}_{3}$ の結晶が成長した. $\mathrm{KCl}$ については, その溶 解度が小さいため成長した結晶は微晶である。 $\mathrm{LiCl}$ は 次の式に示す反応が起り目的結晶はえられなかった。

*この場合の最高温度と は，右図のような温度プ ログラムにおける $T_{\max }$ として表明するように， 試料觉加熱して所定温度 に達してから徐冷開始安


での一定温度を指す．今後，しばしばこの言葉が使用され るので*印を付して最高温度*で表明することとする。 
すなわち，

$$
2 \mathrm{LiCl}+\mathrm{CaSiO}_{3} \rightarrow \mathrm{Li}_{2} \mathrm{SiO}_{3}+\mathrm{CaCl}_{2}
$$

また, $\mathrm{CaCl}_{2}$ では $2 \mathrm{CaO} \cdot \mathrm{SiO}_{2}$ が成長し，フラックス として適当でない。

以上の結果からフラックスとして最も適当な $\mathrm{NaCl}$ を 使用し, 前記 2.3 項の溶解度測定方法によって $\mathrm{CaSiO}_{3}$ の溶解度を求めた. 図一 2 にその溶解度曲線を示寸. 図 から明らかなように，1010 $\mathrm{C}$ では $0.09 \% ， 1190^{\circ} \mathrm{C} て ゙$ は $0.42 \%$ となる。

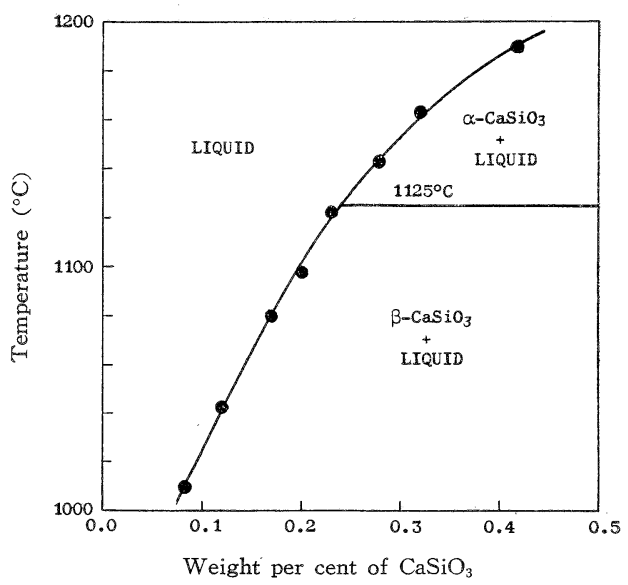

Fig. 2. Solubility curve of $\mathrm{CaSiO}_{3}$ in $\mathrm{NaCl}$.

\section{2 結晶の成長}

すでに判明したように，この実験では溶解度が非常に 小であるため, フラックスに溶解飽和されている溶質量 のみでは有効な結晶の晶出は期待できない，したがっ て, 溶解度より過剩であるが，フラックスに対して 2 3\%の出発原料を使用して実験を行なった．えられた結 果は表一1 亿総括する．以下実験結果を説明する。

3.2.1 最高温度*の影響 試料を $1125^{\circ} \mathrm{C}$ 以下の最 高温度*から徐冷すれば $\beta-\mathrm{CaSiO}_{3}$ のみ成長し, $1125^{\circ} \mathrm{C}$ 以上の場合は, $\alpha-\mathrm{CaSiO}_{3}<\beta-\mathrm{CaSiO}_{3}$ の結晶が同時 に成長する。すなわち， $1150^{\circ} \mathrm{C}$ からは $\beta-\mathrm{CaSiO}_{3}$ の結 晶が多数成長し， $1200^{\circ} \mathrm{C}$ からは，少数で㐫るが大きい
結晶がえられた。これらえられた結晶組成を詳しく知る ため X 線回折により調べた。結果は図一3に示す。 $1125^{\circ} \mathrm{C}$ 以上では, 最高温度*の増加につれて $\beta-\mathrm{CaSiO}_{3}$ が減少し， $\alpha-\mathrm{CaSiO}_{3}$ が増加する. 最高温度* $1200^{\circ} \mathrm{C}$, 24 時間の保持では $\mathrm{X}$ 線的には $\beta-\mathrm{CaSiO}_{3}$ 注見られな い.しかし $1300^{\circ} \mathrm{C}$ の最高温度*では， $\beta-\mathrm{CaSiO}_{3}$ の回 折図のみえられた。このえられたものを顕微鏡観察に供 した結果，球状を呈した $\beta-\mathrm{CaSiO}_{3}$ の微結晶の集合体が 認められた。また，微結晶の間にはガラス相が観察され

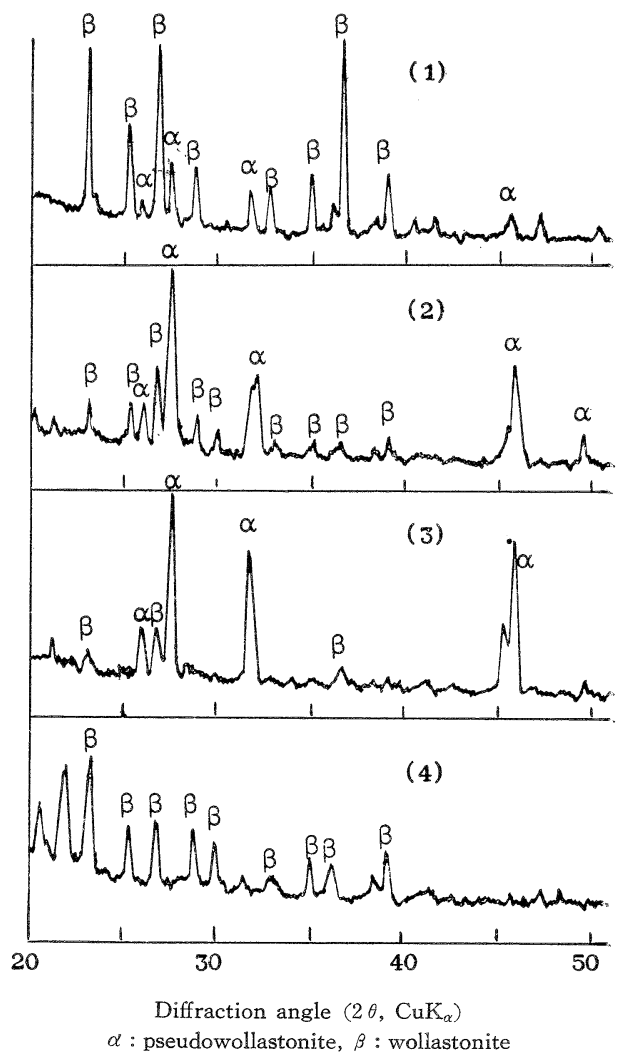

(1) Exp. 6. (2) Exp. 8. (3) Exp. 10. (4) Exp. 11.

Fig. 3. X-ray diffraction patterns of the products: in the bottom of the crucible.

Table 1. Summary of Crystal Growth of Wollastonite in the System $\mathrm{NaCl}-\mathrm{CaSiO}$.

\begin{tabular}{|c|c|c|c|c|c|c|c|c|c|c|c|}
\hline \multirow{2}{*}{$\begin{array}{l}\text { Exp. } \\
\text { No. }\end{array}$} & \multicolumn{3}{|c|}{ Composition } & \multicolumn{2}{|c|}{ Soaking } & \multirow{2}{*}{$\begin{array}{l}\text { Cooling } \\
\text { rate } \\
\left({ }^{\circ} \mathrm{C} / \mathrm{hr}\right)\end{array}$} & \multirow{2}{*}{$\begin{array}{l}\text { Quenching } \\
\text { temp. } \\
\left({ }^{\circ} \mathrm{C}\right)\end{array}$} & \multicolumn{2}{|c|}{ Result* } & \multicolumn{2}{|c|}{ Crystal size** } \\
\hline & $\mathrm{CaSiO}_{3}$ & (g) & $\underset{(\mathrm{g})}{\mathrm{NaCl}}$ & $\begin{array}{l}\text { Temp. } \\
\left({ }^{\circ} \mathrm{C}\right)\end{array}$ & $\begin{array}{l}\text { Time } \\
\text { (hr) }\end{array}$ & & & $\alpha-\mathrm{CS}$ & $\beta-\mathrm{CS}$ & $\begin{array}{l}\text { Length } \\
(\mathrm{mm})\end{array}$ & $\begin{array}{c}\text { Diameter } \\
(\mathrm{mm})\end{array}$ \\
\hline 1 & $\mathrm{SiO}_{2}+\mathrm{CaCO}_{3}$ & 0.5 & 20 & 1000 & 24 & 5 & 800 & - & - & - & - \\
\hline 2 & & 0.5 & 20 & 1200 & 24 & 5 & 840 & ++++ & + & 1.4 & 0.05 \\
\hline 3 & & 0.6 & 20 & 1230 & 1 & 5 & 776 & - & - & - & - \\
\hline 4 & $\alpha-\mathrm{CaSiO}_{3}$ & 0.8 & 45 & 1150 & 2 & 5 & 800 & ++ & +++ & 5.4 & 0.3 \\
\hline 5 & Synthetic & 0.8 & 40 & 1090 & 24 & 5 & 780 & - & +++ & 6.0 & 0.15 \\
\hline 6 & $\beta-\mathrm{CaSiO}_{3}$ & 0.8 & 45 & 1150 & 2 & 5 & 805 & + & ++++ & 4.4 & 0.2 \\
\hline 7 & & 1.0 & 45 & 1080 & 48 & 5 & 860 & - & ++ & 5.0 & 0.15 \\
\hline 8 & Natural & 0.4 & 20 & 1200 & 0 & 5 & 850 & +++ & ++ & 5.0 & 0.2 \\
\hline 9 & & 0.4 & 20 & 1200 & 24 & 5 & 860 & ++++ & + & 6.0 & 0.3 \\
\hline 10 & & 1.0 & 45 & 1200 & 24 & 5 & 880 & ++++ & + & 5.5 & 0.3 \\
\hline 11 & $\beta-\mathrm{CaSiO}_{3}$ & 0.4 & 20 & 1300 & 2 & 5 & 860 & - & - & - & - \\
\hline 12 & & 0.4 & 20 & & const & temp. & hrs) & - & + & 0.2 & 0.03 \\
\hline
\end{tabular}

* Relative proportions of wollastonite ( $\beta$-CS) and pseudowollastonite $(\alpha-\mathrm{CS})$ crystals in the products.

** Crystal size of wollastonite. 
た。な㧍，以上述べた結果の理由については，4の考察 の項で述べる。

3.2 .2 出発原料の影響 前記 2.1 項で出発原料の 調製法について説明したが，実験の結果 (1) (4) の出発 原料中で，(3)抢よび(4)の $\beta-\mathrm{CaSiO}_{3}$ は $\beta-\mathrm{CaSiO}_{3}$ の結 晶の成長が最もよく, また(1)の $\mathrm{SiO}_{2}$ と $\mathrm{CaCO}_{3}$ の等モ ル混合物および (4)では $\alpha-\mathrm{CaSiO}_{3}$ の結晶が多数成長す る傾向にある。

3.2.3 白金暏堝中における結晶の 晶出状況結晶 の晶出状況は, 図一4 の模型図加らかるよらに, 咕堝 の上部の壁に $\beta-\mathrm{CaSiO}_{3}$ の大きい結晶が成長する。こ れは自然発生的にできた核から成長したものと考えられ

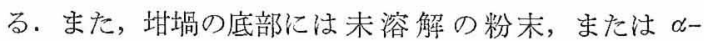
$\mathrm{CaSiO}_{3}$ および $\beta-\mathrm{CaSiO}_{3}$ などの比較的小さい結晶から なる集合体が沈澱する。

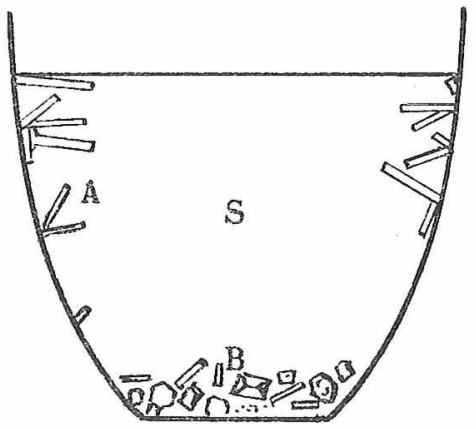

A-large needle-shaped wollastonite crystals.

B-small wollastonite and pseudowollastonite crystals.

$\mathrm{S}-\mathrm{NaCl}+\mathrm{CaSiO}_{3}$ solution.

Fig. 4. Schematic arrangement of grown $\mathrm{CaSiO}_{8}$ crystals in the crucible.

\section{3 成長した結晶の観察}

\subsection{1 $\beta-\mathrm{CaSiO}_{3}$ 結晶 えられた $\beta-\mathrm{CaSiO}_{3}$ の結} 晶を図一 5 に示す，図加わかるように，結晶の表面は 伸長方向に粗雑な条線を有し，針状を呈する．この結晶 そついて，X 線振動写真(図一6) をとって調べた結果, 成辰方向は $b$ 軸方向であることがわかった，その他格子 常数は，三斜晶系の $\beta-\mathrm{CaSiO}_{3}$ の従来のデータと一致 しだ，図一7に示すように，双晶もまれに成長する。

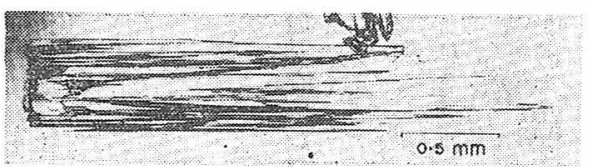

Fig. 5. Single crystal of wollastonite grown from $\mathrm{NaCl}$ flux by slow cooling at a rate of $5^{\circ} \mathrm{C} / \mathrm{hr}$ after soaking at $1200^{\circ} \mathrm{C}$ for 24 hours.

成長した多数の結晶の中から比較的大きいものを，5 〜 6 個えらび，直径と長さを実測して平均の大きさを求 め最高温度*との関係を図一8にあらわした。この図お よび図一9〜10から明らかなように，長さについては最
高温度*の高低に関係なく 5 6 mm とほぼ一定してい る.しか乙直径について放， $1080^{\circ} \mathrm{C}$ で約 $0.1 \mathrm{~mm}$, $1200^{\circ} \mathrm{C}$ では約 $0.3 \mathrm{~mm}$ と順次大きくなる傾向にある。

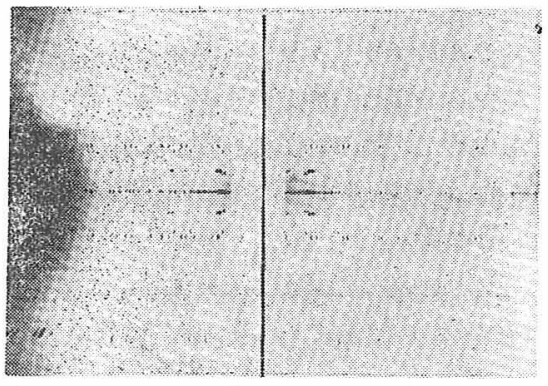

Fig. 6. X-ray oscillation photograph pattern of wollastonite.



Fig. 7. Twinned wollastonite crystal.

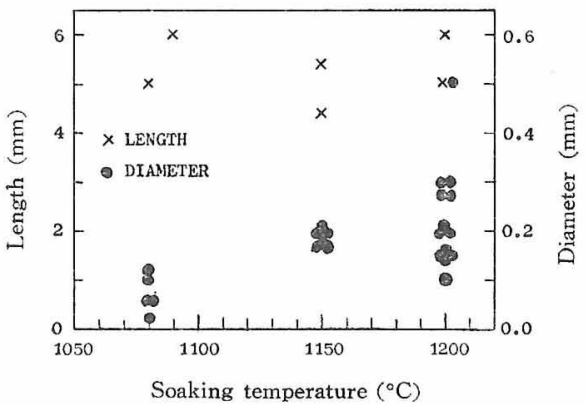

Fig. 8. Crystal size of wollastonite vs. soaking temperature.

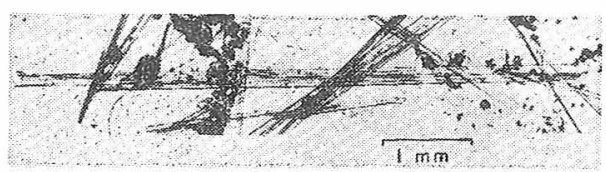

Fig. 9. Single crystal of wollastonite grown from $\mathrm{NaCl}$ flux by slow cooling at a rate of $5^{\circ} \mathrm{C} / \mathrm{hr}$ after soaking at $1080^{\circ} \mathrm{C}$ for 48 hours.

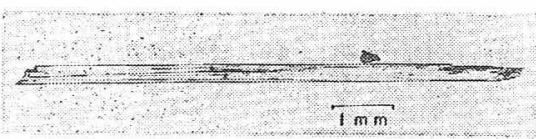

Fig. 10. Single crystal of wollastonite grown from $\mathrm{NaCl}$ flux by slow cooling at a rate of $5^{\circ} \mathrm{C} / \mathrm{hr}$ after soaking at $1200^{\circ} \mathrm{C}$ for 24 hours. 
3.3.2 $\alpha-\mathrm{CaSiO}_{3}$ 結晶 $\alpha-\mathrm{CaSiO}_{3}$ 結晶议, 图一11 加明らかなよらに六角板状を示す。大きさについて は，最高温度*が $1150^{\circ} \mathrm{C}$ で直径 $0.1 \mathrm{~mm}, 1200^{\circ} \mathrm{C}$ では $0.2 \mathrm{~mm}$ であった。

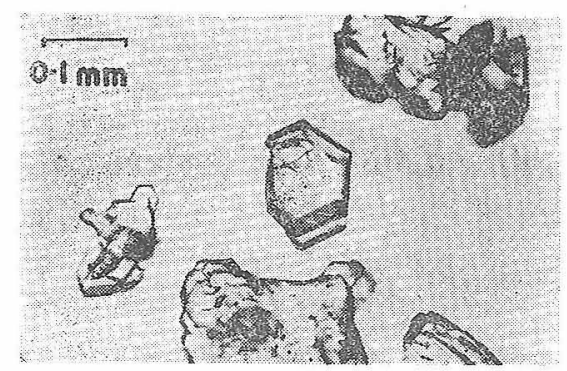

Fig. 11. Pseudowollastonite crystal grown from $\mathrm{NaCl}$ flux by slow cooling at a rate of $5^{\circ} \mathrm{C} / \mathrm{hr}$ after soaking at $1200^{\circ} \mathrm{C}$ for 24 hours.

\section{4. 考察}

最高温度*が $1125^{\circ} \mathrm{C}$ 以上での結晶成長の場合, 徐冷 中通過しなければならない $\alpha \rightleftharpoons \beta$ の転移点 $1125^{\circ} \mathrm{C}$ にお ける $\mathrm{CaSiO}_{3}$ の溶解度は $0.24 \%$ で，これは最高温度*の ちがい恼っても，等しいはずである。したがって， $\beta-$ $\mathrm{CaSiO}_{3}$ の結晶成長に関しては，最高温度*による差は 少ないと考えられる。しかし，実際には最高温度*のち がいは結晶の収量，大きさなどに相当影響を及ぼしてい る.この原因を結晶核発生の多少によるものと推定し $\tau$, 出発原料を $\beta-\mathrm{CaSiO}_{3}$ として, つぎのように考察 した。すなわち，

（a）最高温度*が $1150^{\circ} \mathrm{C}$ の場合

$1150^{\circ} \mathrm{C}$ では $\alpha-\mathrm{CaSiO}_{3}$ が安定なはずである。しか


る $=1150^{\circ}-1125^{\circ}=25^{\circ} \mathrm{C}$ で小さい. 以上 (1), (2) の理由か ら $\beta \rightarrow \infty$ の転移は充分でない. しかも，ここで転移した 部分も結晶子が小さいため転移点以下では容易に $\beta$ へ戻 る. 結局, 過剩成分である沈測物壮 $1125^{\circ} \mathrm{C}$ 以下では大 部分 $\beta-\mathrm{CaSiO}_{3}$ として存在するので，これが多数の核 となって結晶が多数成長する，したがって，えられた個 々の結晶粒は比較的小さいものとなる。

(b) 最高温度*が $1200^{\circ} \mathrm{C}$ の場合

この場合は，転秋点との差は $\Delta T_{2}=1200^{\circ}-1125^{\circ}=$ $75^{\circ} \mathrm{C}$ で大きいため, $\beta \rightarrow \alpha$ の轱移も充分に行なわ礼，ま た，徐冷に際しても $1125^{\circ} \mathrm{C}$ までの間に $\alpha-\mathrm{CaSiO}_{3}$ の 結晶成長が進み，安定になるため， $\alpha \rightarrow \beta$ 転移はおこら ず，室温まで持ちこされる，したがって，この場合法沈 測物中には $\beta-\mathrm{CaSiO}_{3}$ の結晶核柱存在しない。事実, 実験に祘いても，沈澱物中には $\beta-\mathrm{CaSiO}_{3}$ の結晶法成
長しなくて，坩堝上部の壁へ自然発生的に生じた少数の 核から成長したと思われる少数の大きい結晶だけがえら れた。また上記考察の裹付けとして，つぎの事実とも一 致する。すなわち，実験で光られた $\alpha-\mathrm{CaSiO}_{3}$ は $\beta$ $\mathrm{CaSiO}_{3}$ はそれぞれ独立した個々の結晶粒として存在し ていた。 また出発原料として $\alpha-\mathrm{CaSiO}_{3}$ を使用し最高温 度*が $1150^{\circ} \mathrm{C}$ の場合と， $\beta-\mathrm{CaSiO}_{3}$ を使用し最高温度*が $1200^{\circ} \mathrm{C}$ の場合とではほぼ同様の結果がえられている。

（c）最高温度*が $1300^{\circ} \mathrm{C}$ の場合

高温のため $\mathrm{CaSiO}_{3}$ は一部分が $\mathrm{NaCl}$ と反応してガ ラスとなる。これが $\alpha-\mathrm{CaSiO}_{3}$ の結晶成長を妨げ，微 結晶のままであるので，徐泠によって $\beta-\mathrm{CaSiO}_{3}$ に䎐 移したものと考光られる。この反応は $1230^{\circ} \mathrm{C}$ 以上でい ちじるしい。

\section{5. 結論}

アルカリ祘よびアルカリ土類の塩化物をフラックスと して, 徐冷法によりウォラストナイトの結晶成長を試み たところ,つぎのような結果がえられた。

（1）ウォラストナイトの単結晶を成長させるには， (®フラックスとしては，アルカリーアルカリ土類の塩化 物中で $\mathrm{NaCl}$ が適当であり, (b)出発原料には合成した $\beta-\mathrm{CaSiO}_{3}$ の使用が最適である。また, (c)フラックスと

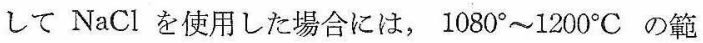
囲に㧍ける最高温度*から徐泠する必要があった。

(2) $\mathrm{NaCl}$ のフラックス中に掠ける $\mathrm{CaSiO}_{3}$ の溶解 度は， $1010^{\circ} \mathrm{C}$ で $0.09 \%, 1190^{\circ} \mathrm{C}$ で $0.42 \%$ と極めて 小さい。したがって，溶解度よりも過剩であるが，フラ ックスにたいして 2 3\% の出発原料を使用して実験を 行なら必要があった。

（3） $1200^{\circ} \mathrm{C}$ の最高温度*から徐冷すれば，自然発生 的に生じた核から大型結晶が，また， $1150^{\circ} \mathrm{C}$ 汃らの徐 冷では過剩の成分である沈澱物を榜として多数の結晶が 成長した.

（4）成長したウォラストナイトは，b朝方向に成長 し, 針状を呈した単結晶で, ま机に注双晶も成長する。 また, 結晶の長さについては最高温度*の高低に関係な く5 6 $\mathrm{mm}$ と一定であるが, 直径は $1080^{\circ} \mathrm{C}$ で約 0.1 $\mathrm{mm}, 1200^{\circ} \mathrm{C}$ で約 $0.3 \mathrm{~mm}$ と最高温度*が高くなるにつ れて大きくなる。

\section{文献}

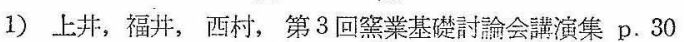
(1965)：吉木文平，鉱物工学，技報童 p. 496 (1959)。

2) H.C. Froelich, J. Electrochem. Soc. 93, 101 (1948).

3) W.H. Grodkiewicz, L.G. Van Vitert, J. Am. Ceram. Soc. 46, 356 (1963).

4) 高橋, 渡辺, 第 14 回応用物理学関係連合講演会合同講演 予稿集 p. 276 (1967).

5）桐山，無機搆造化学 (III), 共立全書p. 137 (1963)。 (5/24/1967 受付) 